\title{
TAMANHO ÓTIMO DE AMOSTRAS DE FRUTOS E DE SEMENTES PARA DETERMINAÇÃO DA POLIEMBRIONIA EM CITROS
}

\author{
CATIANE QUEIROZ DE JESUS SANTOS ${ }^{2}$, EDUARDO AUGUSTO GIRARDI ${ }^{3}$, \\ ELVIS LIMA VIEIRA ${ }^{4}$, CARLOS ALBERTO DA SILVA LEDO ${ }^{3}$, \\ WALTER DOS SANTOS SOARES FILHO ${ }^{3}$
}

RESUMO - Poliembrionia e apomixia nucelar são atributos importantes, tanto no melhoramento e seleção de porta-enxertos de citros, como para sua multiplicação comercial. Avaliou-se a poliembrionia e estimouse o tamanho ótimo de amostras de frutos e de sementes de genótipos de citros para determinar o número de sementes por fruto, número de embriões por semente e taxa de poliembrionia. As plantas-matrizes que forneceram os frutos e sementes estão instaladas na Embrapa Mandioca e Fruticultura, em Cruz das Almas, Bahia. Avaliaram-se: tangerineiras 'Sunki Tropical', 'Sunki Maravilha', 'Sunki da Flórida', 'Sunki Comum', 'Dancy’ e 'Cleópatra'; limoeiros 'Rugoso Jambhiri', 'Rugoso da Flórida', 'Rugoso Comum', 'Volkameriano Lagoa Grande' e 'Cravo Santa Cruz'; e os híbridos limoeiro 'Cravo’ x tangerineira 'Sunki Maravilha', tangerineira 'Sunki da Flórida' x citrangequat 'Thomasville' e híbrido de limeira-ácida 'Tahiti' obtido por polinização aberta. Os resultados foram submetidos à análise estatística descritiva, estimando-se equações de máxima curvatura para determinação de tamanho ótimo de amostras de frutos e de sementes a partir de 20 ou 100 frutos e de 156 sementes por variedade, respectivamente. A produção de sementes e a poliembrionia variaram expressivamente entre os genótipos avaliados, podendo estes serem classificados em cinco grupos de produção de sementes e de taxa de poliembrionia, respectivamente, compreendendo os intervalos de 2 a 28 sementes e de 12 a 100\%. O tamanho ótimo estimado para as amostras foi de nove frutos uniformes, dez e 23 sementes, para determinar, respectivamente, o número médio de sementes por fruto, o número médio de embriões por semente e a taxa de poliembrionia por contagem direta, pois esses valores representam os tamanhos ótimos que atendem a todos os grupos de variedades estudadas.

Termos para indexação: Citrus spp., apomixia, bioestatística, melhoramento genético.

\section{OPTIMUM SAMPLE SIZE OF FRUITS AND SEEDS FOR POLYEMBRYONY DETERMINATION IN CITRUS}

\begin{abstract}
Polyembryony and nucellar apomixis are important traits for citrus rootstocks breeding and selection and for commercial multiplication. This study evaluated the polyembryony and estimated the optimal sample size of citrus rootstocks fruits and seeds for fruit seed number, seed embryo number and polyembryony rate, respectively. Fruits and seeds were collected from mother plants in the experimental field of Embrapa Manioc and Fruitculture, in Cruz das Almas, state of Bahia, Brazil. Rootstock species evaluated were: 'Sunki Tropical', 'Sunki Maravilha', 'Sunki da Florida', 'Sunki Comum', 'Dancy' and 'Cleopatra' mandarins; 'Rugoso Jambhiri', 'Rugoso da Florida', 'Rugoso Comum' and 'Volkameriano Lagoa Grande' lemons; 'Santa Cruz' Rangpur lime; and the hybrids 'Rangpur' lime x 'Sunki Maravilha' mandarin, 'Sunki da Florida' mandarin x citrangequat 'Thomasville' and an open pollinated hybrid of 'Tahiti' lime. Data was submitted to descriptive analysis and equations of maximum curvature were estimated for determination of fruit and seed sample optimal size using 20 or 100 fruits and 156 seeds per genotype, respectively. Seed production and polyembryony varied significantly among the genotypes, which could be grouped by seed production and by polyembryony rate in five classes, respectively comprising intervals of 2 to 28 seeds and 12 to $100 \%$. Optimal size sample was respectively of nine uniform fruits, ten and 23 seeds to determine fruit seed mean number, seed embryo mean number and polyembryony rate by direct counting, because these sample levels were sufficient for all genotypes evaluated.
\end{abstract}

Index terms: Citrus spp., apomixis, biostatistics, breeding.

${ }^{1}$ (Trabalho 063-14). Recebido em: 13-02-2014. Aceito para publicação em: 16-12-2014.

${ }^{2}$ Graduanda em Engenharia Agronômica, Universidade Federal do Recôncavo da Bahia. E-mail: katy.well@hotmail.com. Primeira autora bolsista IC.

${ }^{3}$ Eng. Agr., DSc., Pesquisador A, Embrapa Mandioca e Fruticultura. E-mails: eduardo.girardi@embrapa.br, carlos.ledo@embrapa.br, walter.soares@embrapa.br FAPESB.

${ }^{4}$ Eng. Agr., DSc., Professor Associado, Universidade Federal do Recôncavo da Bahia. E-mail: elvieira@ufrb.edu.br 


\section{INTRODUÇÃO}

Em variedades de porta-enxerto de citros, a elevada produção de sementes é atributo de grande interesse, pois é diretamente proporcional à multiplicação de novas plantas em viveiros. O número de sementes no fruto é determinado por fatores genéticos e ambientais, sendo sua manifestação diferenciada para cada cultivar. Além disso, a maioria das cultivares de citros produz sementes poliembriônicas, devido ao forte potencial embriogênico do tecido nucelar do ovário, que normalmente origina um ou múltiplos embriões adventícios ao redor do embrião sexual, fenômeno denominado apomixia adventícia, em que os embriões adventícios são geneticamente idênticos à planta original (NAKANO et al., 2013).

$\mathrm{O}$ número de embriões encontrados nas sementes de cultivares poliembriônicas é determinado por vários fatores. Além do grau de poliembrionia típico de cada cultivar, a espécie polinizadora, o estado nutricional da planta e a disponibilidade hídrica, por exemplo, podem influenciar na formação dos embriões (SOARES FILHO et al., 2002; KHISORE et al., 2012). Esta variação pode ocorrer ainda entre frutos da mesma planta, em ramos diferentes e em anos diferentes.

$O$ estudo da poliembrionia em portaenxertos de citros é fundamental nos programas de melhoramento genético, pois esse atributo determinará maior ou menor facilidade para a multiplicação do genótipo por semente, a depender de seu grau ser mais ou menos elevado, respectivamente (PASSOS et al., 2006). Assim, um porta-enxerto comercial deve apresentar elevada taxa de poliembrionia, maior número de embriões por semente e alta produção de sementes por fruto. Por outro lado, para obtenção de híbridos por métodos convencionais de melhoramento, a monoembrionia do parental feminino é uma característica preferencial, por implicar a formação exclusiva de indivíduos zigóticos (NAKANO et al., 2013).

A disponibilidade de tempo, mão de obra, recursos financeiros e humanos, muitas vezes, são limitantes à avaliação de grande número de genótipos, pois a análise de muitos caracteres em cada genótipo é comum nos programas de melhoramento genético de plantas. No caso particular da avaliação de sementes e poliembrionia em citros, esta atividade ainda é minuciosa e desgastante. A definição de tamanho ótimo confiável de amostras de sementes e frutos para este tipo de estudo, valendo-se de método estatístico apropriado, é relevante para assessorar os programas de melhoramento genético de citros e, mesmo, para o acompanhamento de plantas-matrizes em campos de produção de sementes.

Portanto, a amostragem de plantas dentro da unidade experimental representa uma alternativa adequada. Os dados da amostra são usados na estimação de parâmetros estatísticos de um caráter em todas as plantas de uma unidade experimental. A diferença entre o parâmetro e a estimativa é denominada erro amostral ou erro de amostragem. $\mathrm{O}$ erro diminui à medida que o tamanho de amostra aumenta. $\mathrm{O}$ uso da amostragem gera um erro dentro da parcela, e esse deve ser minimizado por um tamanho de amostra adequado. $\mathrm{O}$ assunto é básico em ações de melhoramento genético de plantas, dispondo-se de diferentes metodologias para a determinação do tamanho ótimo da amostra (LIMA et al., 2007; MARTIN et al., 2005; PINTO et al., 2000).

Contudo, a literatura não dispõe de recomendações específicas para amostragem de frutos e sementes de citros, sendo utilizados diferentes procedimentos empíricos ou baseados na experiência de melhoristas com determinada variedade. Por conseguinte, este trabalho visou a avaliar a poliembrionia e a estimar o tamanho ótimo de amostras de frutos e de sementes de genótipos de citros para fins de determinação do número de sementes por fruto, número de embriões por semente e taxa de poliembrionia.

\section{MATERIAL E MÉTODOS}

As plantas-matrizes das variedades avaliadas apresentavam idade variando entre 7 e 12 anos e estavam alocadas, em duplicata, em campo experimental a céu aberto da Embrapa Mandioca e Fruticultura, em Cruz das Almas, Bahia (12 40'39'” S, 39 06' 23' W, 226 m, clima tipo BSa, conforme classificação de Köeppen). Os genótipos avaliados foram: tangerineiras 'Sunki [Citrus sunki (Hayata) Hort. ex Tanaka] Tropical', 'Sunki Maravilha', 'Sunki da Flórida' e 'Sunki Comum', tangerineira 'Dancy' (C. tangerina Hort. ex Tanaka), tangerineira 'Cleópatra' (C. reshni Hort. ex Tanaka), limoeiros 'Rugoso (C. jambhiri Lush.) Jambhiri', 'Rugoso da Flórida' e 'Rugoso Comum', limoeiro 'Volkameriano Lagoa Grande' (C. volkameriana V. Ten. \& Pasq.), limoeiro 'Cravo Santa Cruz' (C. limonia Osbeck), além de híbrido de C. latifolia (Yu. Tanaka) Tanaka 'Tahiti CNPMF-01', obtido por polinização aberta (HLATH), e híbridos C. limonia x C. sunki 'Maravilha' (LCR x TSKMA-001) e C. sunki 'Sunki da Flórida' $x$ citrangequat \{Fortunella spp. Swingle $\mathrm{x}$ citrange [C. sinensis (L.) Osbeck x Poncirus trifoliata (L.) Raf.]\} 'Thomasville' (CTQT) (TSKFL 
x CTQT 1439-054). Os tratos culturais usualmente recomendados aos citros foram realizados na área.

As informações utilizadas nas análises constam no banco de dados da instituição, com resultados obtidos de frutos e/ou de sementes coletados entre 2009 e 2012, conforme o portaenxerto. Um total de 6 a 100 frutos foi coletado, considerando-se a presença de sementes totalmente desenvolvidas e sua quantidade por fruto, procedendose ao seu corte equatorial, sem danificar as sementes, para posterior contagem direta das sementes viáveis.

As sementes foram lavadas em água para a retirada da mucilagem e armazenadas em congelador para posterior avaliação em laboratório, sendo caracterizadas quanto ao número de embriões por semente (NES), determinado por contagem direta dos cotilédones das sementes com auxílio de bisturi e lente de aumento 10X, e taxa de poliembrionia (TP), calculada pela percentagem de sementes com mais de um embrião.

Os resultados disponíveis foram anotados para cada fruto ou para cada semente, individualmente, compondo o banco de dados, sendo submetidos à análise estatística descritiva. Os genótipos de citros estudados foram classificados de acordo com o número de sementes por fruto e com a taxa de poliembrionia, determinando-se o número de classes $k$ por $\mathrm{k}=1+3,319 \log _{10}{ }^{n}$, em que: $n$ corresponde ao número de dados avaliados (STURGES, 1926), e a amplitude $w$ de cada classe foi calculada por $w=$ $(M-m) / k$, em que $M$ e $m$ são os valores de dados máximo e mínimo, respectivamente.

Equações de máxima curvatura para determinação de tamanho ótimo de amostras de frutos e sementes foram estimadas pelo método proposto por Lessman e Atkins (1963), e adaptado por Lima et al. (2007), para as variáveis: número de sementes por fruto (NSF), NES e TP, neste caso determinada de forma binária, ou seja, com monoembrionia equivalente a 0 e poliembrionia equivalente a 1 .

Para a determinação do número de embriões por semente e taxa de poliembrionia, optou-se por amostrar sementes ao invés de frutos, pois as contagens são realizadas diretamente em sementes individuais e, em muitas situações, dispõe-se apenas de poucos frutos, como no caso de produções iniciais de novos porta-enxertos obtidos pelo Programa de Melhoramento Genético de Citros da Embrapa Mandioca e Fruticultura, ou dispõese mais facilmente de sementes, como no caso de intercâmbio de genótipos. Desta forma, uma amostra arbitrária inicial de 156 sementes foi avaliada para cada genótipo estudado.
Foram simulados até 31 tamanhos de amostras, em que cada fruto ou semente foi considerado como uma unidade básica, com até 50 frutos ou 50 sementes. Os tamanhos de amostras variaram de 100 a 2 para frutos e de 156 a 2 para sementes.

Pelo método da máxima curvatura modificado, a relação entre o coeficiente de variação $(\mathrm{CV})$ e o tamanho da amostra com $\mathrm{X}$ unidades básicas é explicada pelo modelo $C V=a X^{-b}$, em que a e b são os parâmetros a serem estimados. A partir da função de curvatura dada por esse modelo, determinou-se o valor da abscissa onde ocorre o ponto de máxima curvatura, dada por: $\mathrm{x}_{0}=\exp \{[1 /(2 b+2) \times \log [(a b)$ $2(2 b+1) /(b+2)]\}$, em que: $\mathrm{x}_{0}$ é o valor da abscissa no ponto de máxima curvatura, o qual corresponde à estimativa do tamanho ótimo da amostra (LIMA et al., 2007).

\section{RESULTADOS E DISCUSSÃO}

As variedades estudadas apresentaram variabilidade quanto ao número de sementes por fruto, taxa de poliembrionia e número de embriões por semente (Tabela 1). Cinco classes de genótipos foram formadas em função do número de sementes por frutos: 2 a 7 (tangerineiras 'Sunki da Flórida' e 'Sunki Comum'); 8 a 13 (tangerineiras 'Cleópatra' e 'Sunki Maravilha’ e os híbridos 001 e 054); 14 a 19 (tangerineiras 'Sunki Tropical' e 'Dancy' e limoeiro 'Cravo Santa Cruz'); 20 a 24 (sem genótipos), e 25 a 30 (limoeiro 'Volkameriano Lagoa Grande', as três seleções de limoeiro rugoso e HLATH).

Com relação à taxa de poliembrionia, formaram-se cinco classes também: 12 a 30\% (tangerineira 'Sunki da Flórida'); 31 a 49\% (limoeiro 'Cravo Santa Cruz' e HLATH); 50 a 68\% (híbridos 001 e 054); 69 a 87\% (limoeiros 'Rugoso Comum' e 'Rugoso Jambhiri'), e 88 a 100\% (limoeiro 'Rugoso da Flórida' e tangerineiras 'Cleópatra', 'Sunki Maravilha', 'Sunki Tropical' e 'Dancy'). Os genótipos puderam ainda ser classificados em monoembriônicos (tangerineira 'Sunki da Flórida' e limoeiro 'Cravo Santa Cruz') e em poliembriônicos (demais genótipos), com 2 a 8 embriões por semente em média (Tabela 1)

Genótipos classificados com taxas de poliembrionia médias ou baixas apresentaram alto coeficiente de variação (CV), ou seja, quanto menor a taxa de poliembrionia observada, maior foi o $\mathrm{CV}$ (Tabela 1). Como nesses genótipos houve elevada frequência de sementes com monoembrionia, portanto com valor atribuído igual a zero, provavelmente isso resultou no maior $\mathrm{CV}$ da amostra. Essas variações 
na produção de sementes e na poliembrionia, entre e dentro de variedades, decorrem tanto de causas ambientais, como de precipitação e polinizadores, e de atributos genéticos, estando dentro dos valores previamente relatados para as espécies estudadas (SOARES FILHO et al., 2002; PASSOS et al., 2006; KHISORE et al., 2012; NAKANO et al., 2013).

Para a definição do tamanho ótimo de amostra de frutos para fins de determinação do número de sementes por fruto, utilizaram-se apenas as amostras com 100 frutos por variedade (Tabela 2), pois amostras com 6 a 20 frutos por variedade não resultaram em estimativa precisa $\left(\mathrm{R}^{2}>0,80\right)$ do número de sementes por fruto nos genótipos estudados. Assim, avaliaram-se as variedades limoeiro 'Volkameriano Lagoa Grande', limoeiro 'Cravo Santa Cruz' e tangerineira 'Sunki Comum' por representarem, respectivamente, espécies com alto, médio e baixo número de sementes por fruto (POMPEU JÚNIOR, 2005).

Foram estimadas as equações de máxima curvatura com elevados valores de $\mathrm{R}^{2}$ (Tabela 2 ). O tamanho mínimo ótimo de amostra para fins de determinação do número de sementes de frutos foi de, respectivamente, para os três genótipos avaliados, quatro, cinco e oito frutos. Portanto, quanto maior o número de sementes no fruto, menor o tamanho da amostra ótima necessária, pois verificam-se menores variações unitárias de sementes por fruto e, assim, menores valores de $\mathrm{CV}$.

O total de 156 sementes por genótipo foi adequado para o estudo, estimando-se equações de máxima curvatura com elevados valores de $\mathrm{R}^{2}$ (Tabelas 3 e 4). De maneira geral, cerca de 10 sementes foram suficientes para estimar o número médio de embriões por semente, por contagem direta (Tabela 3). No caso da tangerineira 'Sunki da Flórida', seriam necessárias apenas cinco sementes, pois essa variedade é essencialmente monoembriônica.

Em relação à variável taxa de poliembrionia, os valores de $\mathrm{R}^{2}$ apresentaram-se mais elevados em relação aos verificados para número de embriões por semente, indicando elevado ajuste das equações de máxima curvatura à amostra total de 156 sementes (Tabela 4). A tangerineira 'Dancy' apresentou 100\% de poliembrionia e, assim, o $\mathrm{CV}$ foi equivalente a zero, de modo que não se estimou equação para a taxa de poliembrionia, já que a amostragem é desnecessária neste caso.

Variedades que apresentam alta taxa de poliembrionia resultaram em amostras ótimas pequenas, de três a dez sementes, para a estimação adequada da taxa de poliembrionia por contagem direta (Tabela 4). Por outro lado, quando se avaliaram genótipos com taxa de poliembrionia intermediária, mais sujeita às variações ambientais, além da genética, a amostra ótima foi maior, com cerca de 15 sementes, como no caso do limoeiro 'Cravo Santa Cruz' e do híbrido de limeira-ácida 'Tahiti CNPMF-01'.

Para a tangerineira 'Sunki da Flórida', caracterizada pela menor taxa de poliembrionia observada (12\%), o tamanho ótimo da amostra foi de 23 sementes (Tabela 4). Esse resultado não era esperado, pois, da mesma forma que observado para variedades com alta poliembrionia, esperavase estimar um menor tamanho ótimo de amostra. Contudo, verifica-se evidente correlação positiva $(\mathrm{r}=$ 0,9691 ) entre o tamanho ótimo da amostra e os CVs da taxa de poliembrionia (Tabela 1), indicando que quanto menor a taxa de poliembrionia de uma dada variedade, maior a amostra de sementes necessária para estimar a taxa, pois neste caso há maior frequência de valores iguais a zero (monoembrionia) e, assim, grande variação unitária na taxa de poliembrionia.

A avaliação do número de sementes por fruto e especialmente da taxa de poliembrionia e do número de embriões por semente, por contagem direta, é uma atividade laboriosa, que demanda tempo e esforço prolongados. Os programas de melhoramento genético de citros geram centenas ou até milhares de novos genótipos anualmente, cuja avaliação para fins de seleção de indivíduos promissores, seja de variedades porta-enxerto, seja mesmo de variedades copa, exige o estudo da poliembrionia das sementes. Portanto, a determinação de um tamanho ótimo de amostra de frutos ou sementes é importante para adequada caracterização dos genótipos sem trabalho desnecessário. Em campos comerciais de produção de sementes, a determinação do número de sementes por fruto e da taxa de poliembrionia pode ser necessária para fins de previsão de colheita e planejamento de semeadura de porta-enxertos, de modo que conhecer o tamanho ótimo da amostra de frutos e de sementes é de grande interessante.

Diversos estudos relatam diferentes quantidades de frutos ou de sementes amostrados para a determinação da taxa de poliembrionia e de outros atributos, sendo, pois, necessária uma recomendação padronizada e baseada em critérios estatísticos. Rodrigues et al. (1999) avaliaram 81 e 48 frutos para determinar o número médio de sementes por fruto e a taxa de poliembrionia em quatro cultivares de tangerineira, respectivamente. Soares Filho et al. (2002), caracterizando diferentes seleções de tangerineira 'Sunki', utilizaram 30 frutos 
para determinação de número de sementes por fruto, taxa de poliembrionia e frequência de tamanho de embriões, enquanto Passos et al. (2006) amostraram 15 e 5 frutos para determinar, respectivamente, o número médio de sementes por fruto e a taxa de poliembrionia de diversos porta-enxertos de citros.

Moreira et al. (2010), avaliando P. trifoliata 'Flying Dragon' e híbridos intergenéricos de $C$. limonia x $P$. trifoliata, coletaram 48 frutos para fins de sua caracterização morfológica e estudo da poliembrionia após a germinação em substrato. Em estudo semelhante com $P$. trifoliata e citrumelo (C. paradisi Macfad. x P. trifoliata) 'Swingle', empregaram-se 100 frutos e mil sementes nas análises (RAMOS et al., 2006). Já Guerra et al. (2012), avaliando porta-enxertos comerciais e híbridos de citros, utilizaram 10 frutos e 100 sementes para determinar o número médio de sementes por fruto e a taxa de poliembrionia e número médio de embriões por semente, neste caso tanto pela contagem direta como após germinação em bandejas.

Portanto, a amostragem de frutos e de sementes em diversos estudos com citros poderia ser reduzida sem prejuízo à confiabilidade da avaliação, conforme os resultados do presente trabalho.

TABELA 1 - Ano de coleta (AC), total de frutos coletados (TF), total de sementes viáveis coletadas (TS), número de sementes viáveis por fruto (NSF), número médio de embriões por semente (NES) e taxa de poliembrionia (TP) de porta-enxertos de citros, Cruz das Almas, Bahia.

\begin{tabular}{lccccccccc}
\hline Genótipo & AC & TF & TS & NSF & $\begin{array}{c}\text { CV } \\
(\%)\end{array}$ & NES & $\begin{array}{c}\text { CV } \\
(\%)\end{array}$ & TP & $\begin{array}{c}\text { CV } \\
(\%)\end{array}$ \\
\hline LCR x TSKMA-001 & 2010 & 10 & 95 & 9 & 59,2 & -2 & - & 61,0 & 80,4 \\
Limoeiro 'Cravo Santa Cruz' & 2012 & 100 & 1399 & 14 & 30,0 & - & - & - & - \\
Limoeiro 'Rugoso Comum' & 2009 & 20 & 550 & 27 & 29,1 & 2 & 51,8 & 70,5 & 64,9 \\
Limoeiro 'Rugoso Jambhiri' & 2009 & 20 & 541 & 27 & 30,6 & 3 & 54,8 & 74,3 & 58,9 \\
Limoeiro 'Volkameriano' & 2012 & 100 & 2816 & 28 & 22,4 & - & - & - & - \\
Limoeiro 'Cravo Santa Cruz' & 2009 & 20 & 321 & 16 & 34,2 & 1 & 51,6 & 39,1 & 125,2 \\
Limoeiro'Rugoso da Flórida' & 2009 & 20 & 507 & 25 & 39,9 & 3 & 33,4 & 97,4 & 16,3 \\
HLATH & 2010 & 6 & 156 & 26 & 20,4 & 2 & 50,9 & 40,4 & 121,9 \\
Tangerineira 'Cleópatra' & 2009 & 20 & 245 & 12 & 46,9 & 7 & 53,9 & 96,8 & 18,3 \\
Tangerineira 'Dancy' & 2009 & 20 & 343 & 17 & 30,0 & 8 & 42,4 & 100,0 & 0,0 \\
Tangerineira 'Sunki Comum' & 2012 & 100 & 189 & 2 & 58,1 & - & - & - & - \\
Tangerineira 'Sunki da Flórida' & 2009 & 15 & 80 & 5 & 33,0 & 1 & 29,2 & 12,0 & 272,2 \\
Tangerineira 'Sunki Tropical' & 2009 & 20 & 327 & 16 & 30,9 & 4 & 56,3 & 91,0 & 31,5 \\
Tangerineira'Sunki Maravilha' & 2009 & 20 & 168 & 8 & 33,3 & 8 & 48,1 & 98,7 & 11,4 \\
TSKFL x CTQT 1439 - 054 & 2010 & 10 & 88 & 9 & 33,8 & - & - & 55,0 & 90,9 \\
\hline
\end{tabular}

LCR: limoeiro ‘Cravo’ (Citrus limonia Osbeck); TSKMA: tangerineira ‘Sunki Maravilha' [C. sunki (Hayata) hort. ex Tanaka]; HLATH: híbrido de limeira-ácida 'Tahiti CNPMF-01' [C. latifolia (Yu. Tanaka) Tanaka] obtido por polinização aberta; TSKFL: tangerineira 'Sunki da Flórida’; CTQT: citrangequat \{Fortunella Swingle x citrange [C. sinensis (L.) Osbeck x Poncirus trifoliata (L.) Raf.]\} 'Thomasville'. ${ }^{1} \mathrm{CV}=$ Coeficiente de variação.

${ }^{2}$ Resultados não disponíveis.

TABELA 2 - Coeficientes de determinação $\left(\mathrm{R}^{2}\right)$ e estimativas dos tamanhos ótimos das amostras $\left(\mathrm{x}_{0}\right)$ de frutos para variável número de semente por fruto de porta-enxertos de citros $(n=100)$.

\begin{tabular}{lcc}
\hline Genótipo & $\mathrm{R}^{2}$ & $\mathrm{x}_{0}$ \\
\hline Limoeiro 'Cravo Santa Cruz' & 0,8643 & 5,27 \\
Limoeiro 'Volkameriano Lagoa Grande' & 0,8361 & 3,73 \\
Tangerineira 'Sunki Comum' & 0,9882 & 8,31 \\
\hline
\end{tabular}


TABELA 3 - Coeficientes de determinação $\left(\mathrm{R}^{2}\right)$ e estimativas dos tamanhos ótimos das amostras $\left(\mathrm{x}_{0}\right)$ de sementes de porta-enxertos de citros para a variável número de embriões por sementes $(\mathrm{n}=156)$.

\begin{tabular}{lcc}
\hline Genótipo & $\mathrm{R}^{2}$ & $\mathrm{x}_{0}$ \\
\hline HLATH & 0,9093 & 8,25 \\
Limoeiro 'Cravo Santa Cruz' & 0,8952 & 9,65 \\
Limoeiro 'Rugoso Comum' & 0,9049 & 9,32 \\
Limoeiro 'Rugoso Jambhiri' & 0,9574 & 8,58 \\
Limoeiro 'Rugoso da Flórida' & 0,9424 & 6,90 \\
Tangerineira 'Cleópatra' & 0,8663 & 7,11 \\
Tangerineira 'Dancy' & 0,7569 & 9,38 \\
Tangerineira 'Sunki da Flórida' & 0,8771 & 5,22 \\
Tangerineira 'Sunki Maravilha' & 0,9140 & 8,86 \\
Tangerineira 'Sunki Tropical' & 0,7669 & 10,05 \\
\hline \multicolumn{2}{c}{ HLATH: híbrido de limeira-ácida 'Tahiti' [Citrus latifolia (Yu. Tanaka) Tanaka] obtido por polinização aberta. }
\end{tabular}

TABELA 4 - Coeficientes de determinação $\left(\mathrm{R}^{2}\right)$ e estimativas dos tamanhos ótimos das amostras $\left(\mathrm{x}_{0}\right)$ de sementes de porta-enxertos de citros para a variável taxa de poliembrionia $(n=156)$.

\begin{tabular}{lcc}
\hline Genótipo & $\mathrm{R}^{2}$ & $\mathrm{x}_{0}$ \\
\hline HLATH & 0,8917 & 14,25 \\
LCR x TSKMA -001 & 0,9239 & 10,14 \\
Limoeiro 'Cravo Santa Cruz' & 0,9194 & 15,70 \\
Limoeiro 'Rugoso Comum' & 0,9482 & 10,38 \\
Limoeiro 'Rugoso da Flórida' & 0,9534 & 3,54 \\
Limoeiro 'Rugoso Jambhiri' & 0,9329 & 7,13 \\
Tangerineira 'Cleópatra' & 0,9623 & 4,49 \\
Tangerineira 'Sunki da Flórida' & 0,9844 & 22,92 \\
Tangerineira 'Sunki Maravilha' & 0,9759 & 2,72 \\
Tangerineira 'Sunki Tropical' & 0,8995 & 4,84 \\
TSKFL x CTQT 1439 - 054 & 0,9728 & 12,19 \\
\hline
\end{tabular}

HLATH: híbrido de limeira-ácida 'Tahiti CNPMF-01' [Citrus latifolia (Yu. Tanaka) Tanaka] obtido por polinização aberta; LCR: limoeiro 'Cravo' (C. limonia Osbeck); TSKMA: tangerineira ‘Sunki Maravilha' [C. sunki (Hayata) hort. ex Tanaka]; TSKFL: tangerineira 'Sunki da Flórida'; CTQT: citrangequat \{Fortunella Swingle x citrange [C. sinensis (L.) Osbeck x Poncirus trifoliata (L.) Raf.]\} 'Thomasville'.

\section{CONCLUSÃO}

Recomenda-se coletar aleatoriamente nove frutos uniformes por genótipo, por parcela, visando à contagem do número de sementes e 23 sementes a partir do total coletado para fins de determinação da taxa de poliembrionia e do número médio de embriões por contagem direta.

A depender da quantidade de sementes viáveis presentes por fruto, será necessário coletar maior quantidade de frutos a fim de garantir a amostra recomendada de 23 sementes para a avaliação da poliembrionia.

\section{REFERÊNCIAS}

GUERRA, D.; SCHIFINO-WITTMANN, M.T.; SCHWARZ, S.F.; SOUZA, P.V.D.; WEILER, R.L. Caracterização morfológica, determinação do número de embriões e taxa de poliembrionia em três porta-enxertos híbridos de citros. Bragantia, Campinas, v.71, n.2, p.196-201, 2012.

KISHORE, K.; RINCHEN, M.N.; LEPCHA, B.; PANDEY, B. Polyembryony and seedling emergence traits in apomictic citrus. Scientia Horticulturae, Amsterdam, v.138, p.101-107, 2012. 
LESSMAN, K.J.; ATKINS, R.E. Optimum plot size and relative efficiency of lattice designs for grain sorghum yield test. Crop Science, Madison, v.3, p.477-481, 1963.

LIMA, J.F.; PEIXOTO, C.P.; LEDO, C.A.S.; FARIA, G.A. Tamanho ótimo de parcela para experimentos com plantas de mamoeiro em casa de vegetação. Ciência e Agrotecnologia, Lavras, v.31, p.14111415, 2007.

MARTIN, T.N.; STORCK, L.; LÚCIO, A.D.C.; LORENTZ, L.H. Plano amostral em parcelas de milho para avaliação de atributos de espigas. Ciência Rural, Santa Maria, v.35, n.6, p.1257-1262, 2005.

MOREIRA, R.A.; RAMOS, J.D.; CRUZ, M.C.M. Caracterização de frutos e poliembrionia em sementes de 'Flying Dragon' e de híbridos de porta-enxertos de citros. Revista Brasileira de Fruticultura, Jaboticabal, v.32, n.2, p.486-492, 2010.

NAKANO, M.; KIGOSHI, K.; SHIMIZU, T.; ENDO, T.; SHIMADA, T.; FUJII, H.; OMURA, M. Characterization of genes associated with polyembryony and in vitro somatic embryogenesis in Citrus. Tree Genetics \& Genomes, Heidelberg, v.9, n.3, p.795-803, 2013.

PASSOS, O.S.; PEIXOUTO, L.S.; SANTOS, L.C.; CALDAS, R.C.; SOARES FILHO, W.S. Caracterização de híbridos de Poncirus trifoliata e de outros porta-enxertos de citros no Estado da Bahia. Revista Brasileira de Fruticultura, Jaboticabal, v.28, n.3, p.410-413, 2006.
PINTO, R.M.C.; LIMA NETO, F.P.; SOUZA JÚNIOR, C.L. Estimativa do número apropriado de progênies S1 para a seleção recorrente em milho. Pesquisa Agropecuária Brasileira, Brasília, v.35, n.1, p.63-73, 2000.

POMPEU JÚNIOR, P. Porta-enxertos. In: MATTOS JÚNIOR, D.; NEGRI, J.D.; PIO, R.M.; POMPEU JÚNIOR, P. Citros. Campinas: Instituto Agronômico de Campinas, Fundag, 2005. p. 63-104.

RAMOS, J.D.; ARAÚJO NETO, S.E.; CASTRO, N.E.A.; MARTINS, P.C.C.; CORREIA, M.G. Poliembrionia e caracterização de frutos de citrumelo 'Swingle' e de Poncirus trifoliata. Ciência e Agrotecnologia, Lavras, v.30, n.1, p.88-91, 2006.

RODRIGUES, L.R.; DORNELLES, A.L.C.; WITTMANN, M.T.S. Poliembrionia e número de sementes por fruto de quatro cultivares de tangerineira. Ciência Rural, Santa Maria, v.29, n.3, p.469-474, 1999.

SOARES FILHO, W.S.; MEDRADO, A.C.M.; CUNHA, M.A.P.; CUNHA SOBRINHO, A.P.; PASSOS, O.S. Frequência de híbridos em cruzamentos controlados de citros: cultivo de sementes versus cultivo in vitro de embriões. Pesquisa Agropecuária Brasileira, Brasília, v.37, n.7, p.981-988, 2002.

STURGES, H.A. The choice of a class interval. Journal of the American Statistical Association, New York, v.21, n.153, p.65-66, 1926. 